\title{
Connections Without Command: ESW's Service Learning Approach
}

\author{
Alexander T. Dale* \\ Executive Director \\ Engineers for a Sustainable World \\ Pittsburgh, PA \\ atdale@eswusa.org \\ *Corresponding Author \\ Robert E. Best \\ Projects \& Education Director \\ Engineers for a Sustainable World \\ Mountain View, CA \\ rbest@eswusa.org \\ Justin L. Hess \\ Education Director \\ Engineers for a Sustainable World \\ Indianapolis, IN \\ jhess@eswusa.org
}

\author{
Erin R. Lennox \\ Projects Director \\ Engineers for a Sustainable World \\ Troy, NY \\ erlennox@eswusa.org \\ Denise McKahn \\ Engineering \\ Smith College \\ Northampton, MA \\ dmckahn@smith.edu \\ Michael K. Jensen \\ Mechanical Engineering (Emeritus) \\ Rensselaer Polytechnic Institute \\ jensem@rpi.edu
}

Abstract - Engineers for a Sustainable World (ESW) is a US-based non-profit network that designs and implements technical sustainability projects through a network of collegiate and professional chapters. Although founded around international development, today the organization focuses primarily on domestic projects situated within local campuses and communities. Similarly, ESW operates as a network rather than a hierarchical organization, an organizational model with its own lessons for service learning. This paper outlines the basic structure and function of ESW, and uses three case study projects combined with ESW's recent history to emphasize the importance of service learning organizations on sustainability education. It examines lessons and the value of ESW and similar organizations at the individual level and for the university community, and examines challenges in replicating this model. We show that the diversity of members and autonomy of chapters in ESW's network leads to several benefits, including lower costs per student and entry points for any discipline or career status. Nonetheless, this requires extra effort to build effective engagement and collaboration across chapters and needs continuous monitoring to balance support with control.

Index Terms - case studies, extracurricular, organizations, sustainability

\section{INTRODUCTION}

Sustainability is a broad area that encompasses many complex or 'wicked' problems, including urban planning, supplying energy and water, and global climate change ${ }^{1}$. Addressing these issues 
comprehensively and systemically requires many different disciplines to design and implement appropriate responses; engineers and other technical individuals are a key part of this overarching effort ${ }^{2}$. With these needs in mind, the next generation of technical professionals will need exposure to both sustainability concepts and skills for dealing with complexity, poor problem definition, and multiple stakeholders ${ }^{3,4}$. Service learning represents a key avenue for providing this exposure for both students and professionals.

Engineers for a Sustainable World (ESW) is a US-based non-profit organization (NGO) operating as a chapter-focused network that works toward sustainability through technical design projects, member education, and a shared community. Founded in 2002, ESW has a network of 40 chapters - 37 student and three professional - across the US and Canada, 1000 members, and $\sim 3000$ alumni. ESW's approach to service learning is rooted in a desire for real impact and the simultaneous need to infuse sustainability and associated complex topics into engineering education $^{3}$.

ESW was founded as part of the modern generation of international development organizations. After the founder's departure in 2008 and financial stress from the global recession, the organization restructured its national office into a distributed team of volunteers with a small number of paid staff. During this change, the organization's focus also shifted from primarily international projects towards domestic projects, increased educational programming, and a more network-focused structure. ESW became an independent entity in July 2013, after fiscal sponsorship from the Center for Transformative Action at Cornell and the University of California, Merced, and received 501(c)(3) status in August 2014.

ESW focuses on increasing exposure of technical individuals to all aspects of sustainability background knowledge, improved design skills, new approaches to systems thinking, novel and alternative technologies, economic and social metrics, etc. This is primarily achieved through student-led projects initiated by ESW's chapters and undertaken with the support of university faculty and staff, engineering professionals in the ESW network, and community groups and corporate partners. Unlike traditional engineering or technical curricula, rather than focusing on a specific discipline or stakeholder group, ESW's membership includes all engineering majors and many non-engineers, as well as students, faculty, and professionals. This broader approach allows integration of stakeholder groups, disciplinary concepts, and more robust consideration of complex topics through both extracurricular service learning projects and educational programs like the Wicked Problems in Sustainability Initiative (WPSI), which links project-based courses to a shared problem, set of topical mentors, and digital community ${ }^{5}$.

In addition to projects and newer course-based programs such as WPSI, ESW focuses on community-building and member education through digital media, including online webinars and short courses, activity on social media networks, and a curated opportunity bank. ESW aids in identity formation for technically-minded individuals working on sustainability, with regional and annual conferences co-hosted by local chapters and ESW-National, providing a social space for best practice sharing, networking, and strengthening this shared community. Although ESWNational balances projects, education, and community, due to the nature of this special issue of the International Journal of Service Learning in Engineering (IJSLE), the focus of this manuscript is on the service-learning projects and the lessons that can be gleaned from ESW's approach to student-led projects. 


\section{BACKGROUND}

Engineers for a Sustainable World focuses on service learning projects because they provide a valuable way of exposing individuals to complexity and sustainability topics while making real impacts in communities. ESW primarily engages in extracurricular, student-led projects on campus, in the local community, or internationally. Curricular efforts also exist, both locally and through national initiatives. The basic operation of chapters within the ESW network is presented along with their diversity and general approach to project selection, and the role of ESWNational in supporting chapters. Three case study projects from the campus, community, and international spaces are included. These case studies provide a deeper look at the project scoping, design, and - in two cases - implementation phases, as well as project partners. Lessons learned for both projects and student organizations then follow.

\section{ESW Chapters \& National Network}

ESW's 37 collegiate chapters (as of September 2014) include schools of all kinds, ranging from two-year schools to liberal arts colleges to public and private research universities. Chapters are primarily extracurricular and undergraduate, with graduate participation and faculty involvement on a project-specific basis and varying between chapters. Chapters are generally started by a passionate student or faculty member, and have an average active membership of 25 students, with larger chapters such as Northwestern or SUNY-Buffalo having up to 90 active local members.

Because ESW is structured as a supportive network rather than a hierarchical organization, chapters have significant autonomy in choosing their project topics and local partners. This approach encourages initiatives that match local interest and needs, but allows students to draw on knowledge from elsewhere in the network. Example projects include biofuel production, food waste management, and energy reduction campaigns on campuses; energy audits, renewable energy installations, urban gardens, and rain gardens in the community; and biodigesters, remote refrigeration, and shipping container housing internationally. Since 2008, ESW's projects generally have had a domestic focus, with only $40 \%$ of chapters working internationally.

Local projects range in duration from a few weeks for an outreach event to multiple years, but are normally 1-2 semesters to align with the school year, initiated by connection with an established partner (often campus facilities management, a community group, or an international NGO), and are student-led and extracurricular. Projects occasionally move between coursework and extracurricular chapter management, often by senior design projects developing a previous chapter idea, or via a chapter implementing designs from a project-based course. A select set of established chapters (e.g. Stanford, Cornell, University of Rochester) have also created creditbearing courses for ESW projects. These courses are advantageous because they provide a structured time when students can work on the projects, and often opportunities for faculty or mentors to provide feedback. Limited enrollment or schedule conflicts, however, can limit participation and give preference at some schools to upper class students due to registration protocols. Extracurricular projects usually allow all interested students to become meaningfully involved, but without strong leadership can lack mentorship and project feedback opportunities.

Project teams generally have 6-8 students, with larger projects having multiple sub-teams of this size. An average chapter is likely to have 2-4 projects active at any given time. When additional expertise is required - particularly for international work - faculty or professional 
mentors are often used, and can be provided through ESW-National. Funding is generally provided by small grants or local fundraising - most projects cost $\$ 500$ to $\$ 3,000$ because of their local focus and lack of travel costs. ESW-National offers limited project funding that increases with new overall revenue. In some cases, local projects can cost upwards of $\$ 10,000$ and are often financed by partner organizations, which are commonly the university or a community partner.

ESW's central office plays a stronger role in information sharing, events coordination, and leadership support than in project selection and process approval. ESW-National does provide annual opt-in initiatives, connections to professionals to act as mentors, limited project grants, and support for chapters looking for additional funds. Every chapter has a volunteer Chapter Relations Coordinator (CRC) that acts as a primary contact between the chapter and ESWNational. CRCs meet with chapters individually for several hours per term to help establish school-specific goals, suggest new resources or projects, and connect chapters working on similar projects. CRCs also run monthly small-group calls on leadership topics such as member retention or leadership turnover. Starting in 2014, CRCs also run digital 'project workshops' for chapters undertaking in similar projects (i.e. pilot solar installations on campus) to facilitate greater knowledge sharing within the ESW network.

As of 2014, ESW-National is composed of 24 volunteers and one paid staff member focused on creating programs and support materials to enable impactful projects, educate members, and connect ESW with related groups and organizations for cooperation. The organization is funded by a mixture of chapter and member dues (30\%), conference registrations (34\%), individual donations (25\%), and corporate sponsorships (11\%). This percentage is likely to shift as the organization expands during its first few years of fiscal and legal independence.

\section{Case Study Projects}

To exemplify the role of ESW in facilitating extracurricular service learning, three case studies have been selected that demonstrate the range of projects undertaken by ESW chapters and the outcomes of these projects. The selected case studies exemplify chapter autonomy while simultaneously representing the range of complex topics tackled by many students, the involvement with multiple stakeholders outside of the ESW network, and the broader systems thinking that is facilitated in a way not typically experienced in traditional engineering education. A brief overview of all three case studies is shown in Table I. 
International Journal for Service Learning in Engineering Special Edition, pp. 48-61, Fall 2014

ISSN 1555-9033

TABLE I

An Overview of Selected CASe StUdies For ESW Chapter Projects

Cargo Cycle Vandergrift Redesign Haitian Housing

\begin{tabular}{|c|c|c|c|}
\hline Institution & Smith College & University of Pittsburgh & $\begin{array}{l}\text { Rensselaer Polytechnic } \\
\text { Institute }\end{array}$ \\
\hline Spatial Scope & Campus & Community & International \\
\hline Project Length & Three semesters & Two projects over two years & Two projects over two years \\
\hline Synopsis & $\begin{array}{l}\text { Design and build cargo cycle } \\
\text { for campus catering to } \\
\text { decrease fossil fuel usage }\end{array}$ & $\begin{array}{l}\text { Recommend sustainable } \\
\text { materials and design choices } \\
\text { for building renovations }\end{array}$ & $\begin{array}{l}\text { Design and implement } \\
\text { community facilities for a } \\
\text { Haitian town using shipping } \\
\text { containers }\end{array}$ \\
\hline Partners & Campus Dining Services & $\begin{array}{l}\text { Community Improvement } \\
\text { Program }\end{array}$ & $\begin{array}{l}\text { US Non-profit and Church, } \\
\text { Haitian School }\end{array}$ \\
\hline $\begin{array}{l}\text { Student Learning } \\
\text { Outcomes }\end{array}$ & $\begin{array}{l}\text { Experience with design and } \\
\text { construction, designing for a } \\
\text { specific client's needs }\end{array}$ & $\begin{array}{l}\text { Experience with life-cycle } \\
\text { assessment \& decision } \\
\text { making, public } \\
\text { communication of results }\end{array}$ & $\begin{array}{l}\text { Experience with design and } \\
\text { construction, cultural } \\
\text { exchange, design for a } \\
\text { specific community's needs }\end{array}$ \\
\hline Project Impacts & $\begin{array}{l}\text { Decreased van usage, } \\
\text { visibility on campus }\end{array}$ & Community education & $\begin{array}{l}\text { Broader access to education, } \\
\text { improved medical facilities }\end{array}$ \\
\hline
\end{tabular}

\section{Campus Project: ESW-Smith}

As a signatory on the American College and University Presidents' Climate Action Commitment, Smith College is dedicated to substantive carbon footprint reductions on an arc toward becoming a carbon neutral campus. Smith College ESW students have initiated a number of projects specifically targeting reductions in carbon emissions that result from the operation and maintenance of the campus.

One such project was the design and construction of the Cargo Cycle, a human-powered delivery vehicle used by Smith College's Catering Services. Catering Services previously had a single large truck powered by fossil fuel combustion. The truck was used regardless of the size of the catering event. Catering Services sought a smaller custom vehicle that could be driven along the numerous pedestrian pathways at Smith. An additional quality of life benefit came from providing Catering staff an opportunity to exercise while on the job. 


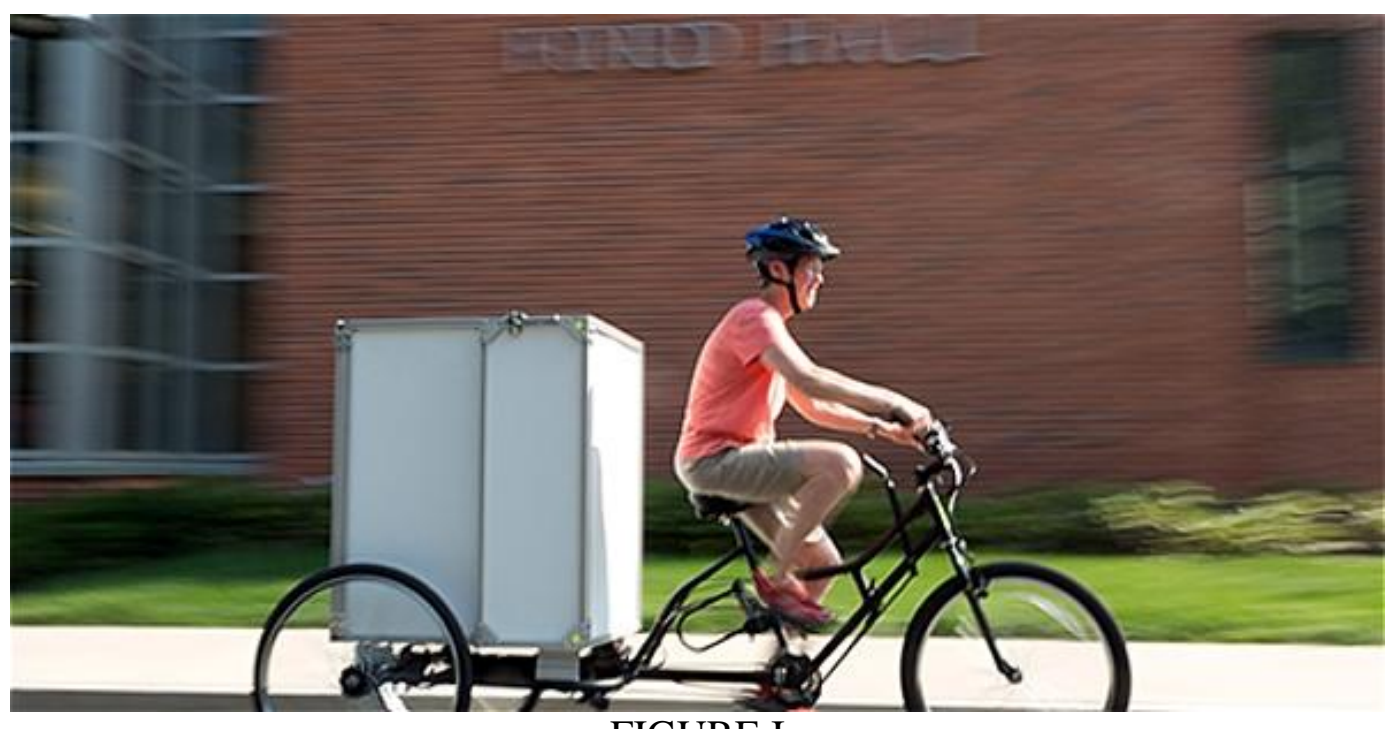

FIGURE I

THE FINAL CARGO CYCLE IN OPERATION, WITH CUSTOM-SIZED CARGO CONTAINER.

Spearheaded and managed by Peace Young '12 over the course of two years (2011-2013), several Smith College ESW students were involved in designing, fabricating, and testing the Cargo Cycle prior to delivery to Catering Services. Some students could only contribute a few hours over a single weekend, while others were able to truly dedicate a substantive amount of time. All students were considered essential to the project, but expectations were adjusted based on the honest assessment of an ability to commit to the project. Funding for the project was provided by the Smith College Catering Services, Smith College Office of Sustainability, and the MIT Vehicle Design Summit.

Students first selected and purchased an existing trike chassis that was designed as a pedalpowered taxi by Cascadia Pedicabs. The cab was removed and the vehicle was re-geared to enable smoother steering and climbing. A storage container was then designed and built with an 80/20 extruded aluminum structural framing system to accommodate cookie trays, air pots, fruit baskets, and other required items. The Cargo Cycle was delivered to Catering Services in the Fall of 2013 and Catering staff were trained in the operation and handling of the three wheeled vehicle $^{6}$. Since transferring the Cargo Cycle to Catering staff a number of lessons were learned. First, the Smith College campus is expansive with a significant distance between the Catering kitchen and the campus buildings served. Additionally, the cargo section was top-heavy, creating a driver perception of imbalance. Modifications are currently being considered to reduce the load carrying capacity and height of the cargo section. Despite numerous surveys and interviews that took place during the design process, these lessons allowed students the opportunity to explore what happens when the wheels hit the road!

\section{Community Project: ESW-Pitt}

Vandergrift, Pennsylvania, is a community of 5,000 residents northeast of Pittsburgh. Planned by Frederick Law Olmsted and once home to the largest sheet steel mill in the world, the town declined along with the U.S. steel industry in the 1980s. As part of ongoing municipal revitalization efforts, town leaders chose to emphasize sustainability in local government. From 
2006-2011, 40 students from the University of Pittsburgh (Pitt) worked with the Vandergrift Improvement Program (VIP) on a variety of efforts, including improving energy efficiency in an historic theater and testing non-turbine methods for generating electricity from the fast-flowing Kiskiminetas river that loops around the town ${ }^{7}$. The central ESW-Pitt project in this ongoing partnership was the redesign of sections of two main street buildings using green building techniques and sustainability principles such as the Natural Step ${ }^{8}$. Each building was a focus of a year-long project during the 2009-2010 and 2010-2011 school years.

The first building was a former department store that had been stripped to the masonry walls and wooden floors. ESW-Pitt was part of a larger planning effort to reimagine the building as a community space and business incubator, with students focusing on a half-floor landing overlooking the main lobby (see Figure 1). Over the course of a school year, a team of $\sim 10$ students learned about life-cycle assessment (LCA), researched potential materials for windows, acoustics, seating, and insulation using LCA as a decision tool, and compiled a plan for a flexible community space including visual mock-ups and material recommendations. The results were presented to the town at a public event attended by 40 people.

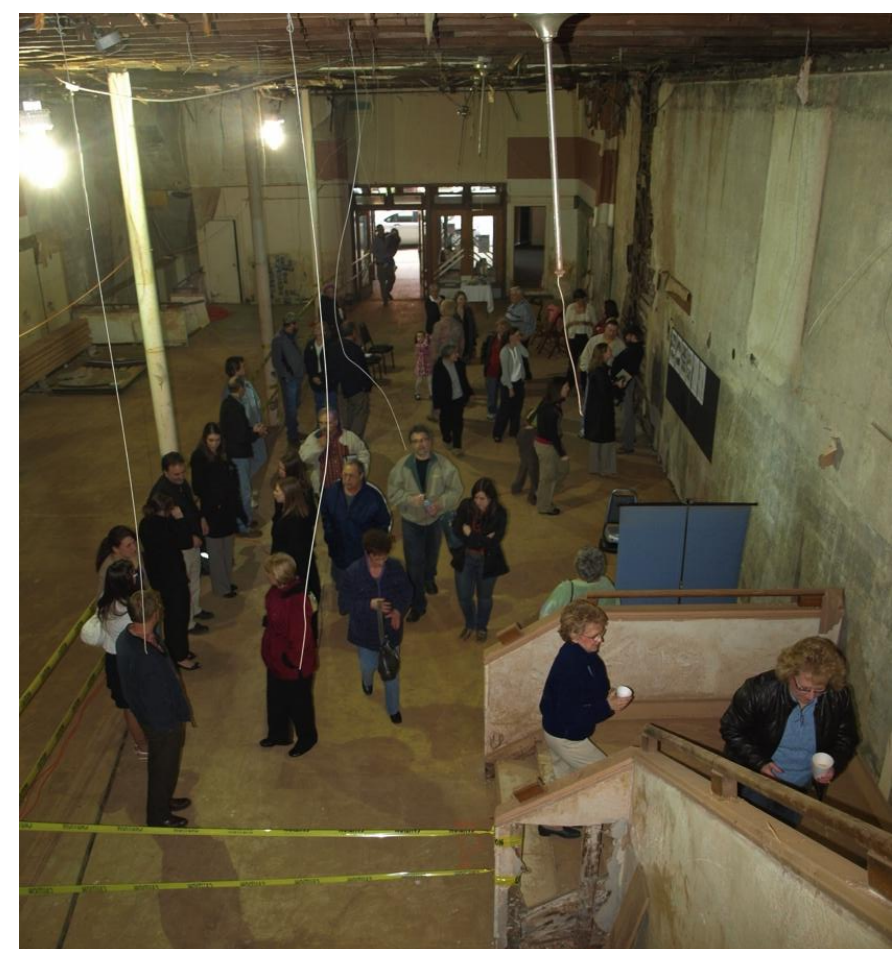

FIGURE II

ATTENDEES AT THE PUBLIC PRESENTATION FOR THE DEPARTMENT STORE REDESIGNED

Following the successful presentation, ESW-Pitt was asked to work on a second building, located across Main Street from the first, which was to be renovated into energy-efficient and affordable housing for senior citizens. A team of new and returning students worked on basic floor plans using some of the material choices from the initial building. Additional effort focused on heating and energy options, including biomass, geothermal wells, and rooftop solar. The final result was a recommendation that weatherization combined with photovoltaics and a small biomass furnace provided the best combined environmental and economic option. A similar 
public event was held for the residents, and the project was covered by the regional newspaper.

In both cases, participating students gained experience assessing tradeoffs in environmental and economic impact of materials, researching options and connecting with local businesses and residents, and preparing and presenting results that meet community interests. However, neither design has been implemented because VIP has not had the funds or resources for grant-writing available. Long-term impacts from these projects were thus low, though the project was considered a success in terms of student learning.

\section{International Projects: ESW-Rensselaer}

The Rensselaer Polytechnic Institute (Rensselaer) chapter of ESW has made four service trips to Haiti since 2009. Working in concert with individuals from St. John's Episcopal Church in Troy, NY, and an NGO, To Love a Child, of Clifton Park, NY, teams of students and professors have worked on solar PV installations at several locations, a computer classroom (2010), aquaponic food systems (2011), housing for a small medical clinic (2012), and a daycare center ${ }^{9}$ (2013). The church and NGO maintain regular contact with the community, and were responsible for identifying potential projects based on community needs. ESW-Rensselaer then selected projects that fit chapter capabilities and took the lead on design and development, with the exception of communication with the Haitian community, which was maintained through the long-term connection of the NGO.

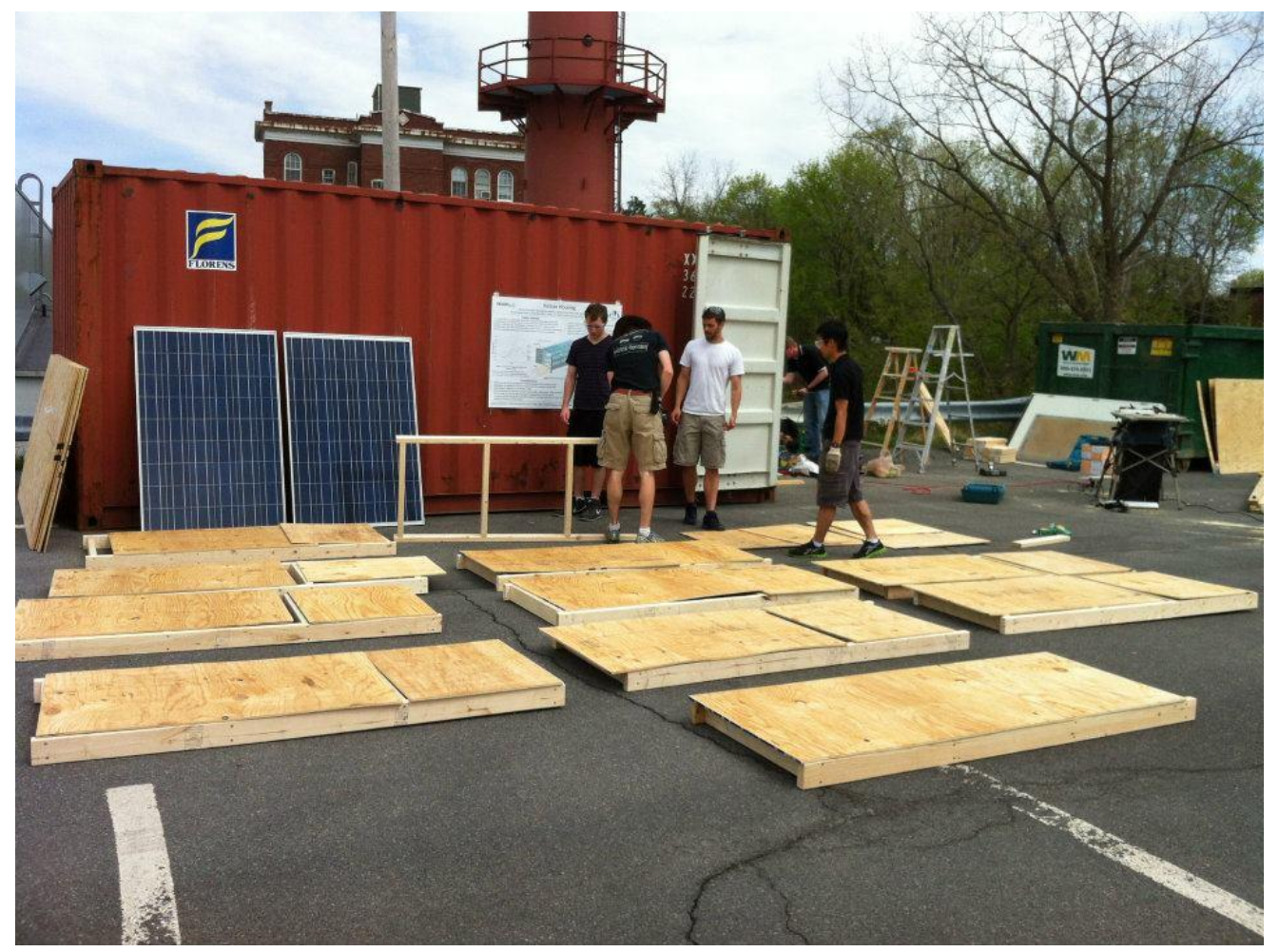

FIGURE III

RENSSELAER STUDENTS AT THE BEGINNING OF CONSTRUCTION IN THE US. SOLAR PANELS, THE UNPAINTED CONTAINER, AND WOOD FOR HOSPITAL BEDFRAMES ARE ALL VISIBLE. 
The latter two projects are located in Rantlamouaie, a small village in the backcountry of Haiti without running water or electricity. The projects involved the conversion/modification of two $8 \mathrm{ft}$ by $8 \mathrm{ft}$ by $20 \mathrm{ft}$ shipping containers. The first provides housing for patients and caregivers utilizing a small medical clinic previously housed near the church school. The second provides daycare space for small children so their older brothers and sisters can attend school in the village instead of babysitting their siblings. The approach makes use of local materials since supplies (e.g., baby beds, mattresses, crutches, toys, clothing, etc.) are shipped to Haiti in large metal containers, but because there are no products to ship out of Haiti, the containers are left on the docks to rust away. By converting the containers, a waste product is turned into usable living space.

St. John's has a long-term relationship with a church school in Lascahobas (a town about 75 $\mathrm{km}$ from Port-au-Prince), and the school in Rantlamouaie is a satellite facility to Lascahobas. The executive director of To Love a Child has worked extensively with St. John's, with the school administration in Lascahobas, and the village elders in Rantlamouaie to understand the needs of the village, to balance those needs against the resources and personnel available with ESW and other groups, and to coordinate the development of the projects.

Since the work was done by college students, the conversion of each container (design work, procurement of materials, and construction) took about nine months. The second container's modifications took less time because of incorporation of lessons learned from the first one. Progress depended on the number of students available for work, class loads, etc. In each case, the container conversions were completed in time for donated materials and supplies to be loaded into the containers and shipped to Haiti by mid-May. When the group traveled to Haiti to install the facilities, about one week was needed to finish the project. Reports from Rantlamouaie have indicated that the villagers are very happy with the final configuration and utility of the facilities. During a chapter trip in early October 2014, both facilities were in constant use, with a third project underway. Both container projects are in need of some repairs, and the regular visits provide both a chance to start repairs and to monitor use and progress.

\section{DISCUSSION AND LESSONS LEARNED}

These projects from ESW chapters at Smith, Pittsburgh, and Rensselaer depict how students developed leadership experience and cultural competence while working on sustainabilityrelated projects in both domestic and international settings. While international development poses a wide range of monumental challenges - clean water, sanitation, access to renewable energy, etc. - there is a strong case for sustainability (rather than development) focused organizations like ESW to work within highly developed countries that account for the bulk of the global impacts, and often face similarly complex cultural challenges around poverty, embedded infrastructure (e.g. suburbs), and/or diverse stakeholder groups. The largely domestic spatial scope of ESW's projects as a network creates strong connections to students' local communities that they otherwise would not have achieved, as in the ESW-Pitt example. Costs for domestic projects are also significantly lower without the need for airfare or international preparation (for comparison, consider the cost of the Smith Catering Services vehicle relative to the Haiti shelters).

While the scale of domestic projects is often smaller than international work, greater percentages of students can be involved throughout the project lifetime due to the local nature of the project, and the end results are more easily maintained over time. Greater student 
involvement is especially beneficial when learning goals and student attainment (e.g., project leadership, sustainable design, and working with diverse stakeholders) are balanced as a focus with sustainability impacts. This was documented by both the Smith and Pitt project leaders. Defining success partly through student learning, regardless of final implementation, could be seen as the 'long game' - getting many students involved in sustainability, both through service learning and through semi-applied coursework, so that regardless of their future vocation or career path, they push technical sustainability into design, policy, and construction.

Informal surveys of student members over the last 5 years have consistently shown that individuals join ESW because they wanted to 'do something', often in contrast to environmental activist groups with a less technical or project-based focus. Relative to international development organizations, ESW's members are less motivated by helping impoverished communities, and often more focused on implementing appropriate technologies in the developed world - clean energy, green chemistry, and water systems being common interests. The large number of internationally-focused organizations has allowed ESW to find a different niche - under a different focus of 'sustainability' - in domestic projects with a range of technological complexity, while still engaging students in complex issues and service learning.

\section{Lessons Learned}

ESW's projects occupy a wide range of disciplines, geographic scopes, and topics, which is our goal as a topical rather than professional or international organization. There are, however, overarching lessons for both improving domestic and extracurricular service-learning projects and strengthening service-learning student organizations as a whole. Project lessons come from the case studies above, while lessons for student organizations come from ESW's years of experience in this space. We have attempted to focus on lessons that are more unique to autonomous, domestic, or sustainability efforts, instead of international and more centrallymanaged impacts.

\section{Individual Projects}

Partner buy-in is everything. All long-term impact is based on successful relationships during project design. Without buy-in by the partner - whether a Community Development Corporation or Haitian village - a project will not be successful. Put another way, if the project is not something that the stakeholders want, will use, and maintain, then the donor groups and students are wasting their time. This principle is the core of human-centered design, but is often lost among students that insist on doing a project around a specific topic or approach; reinforcing this lesson is an important aspect of a service learning experience for many students.

Scope projects with professional help. Advice and guidance to the student group by an experienced person on a realistic project scale and goal is useful and often missed by students. Having a long-term mentor's experience is beneficial throughout the process to help facilitate the actual design, specifications, and construction process. All three case studies were feasible because the right scope was set at the beginning, particularly the Haitian work by ESWRensselaer. Students benefit from learning topics that go beyond curricula and from direct contact with technical professionals. 
Treat student learning and project impact separately. Students will learn regardless of successful implementation, via cultural exchange, research into materials or techniques, and working within a team. Actual impact is dependent on other factors. In international projects where on-theground time is limited, an experienced individual (i.e., someone who has the skills to ensure successful implementation and is not afraid to make decisions on the fly) is likely to make the difference. In domestic projects, early identification of funds for implementation will shift projects from an interesting design exercise (e.g. ESW-Pitt and the VIP) to lasting change.

Domestic projects mean more people can participate. International projects are often inherently more attractive than local efforts because of the prospect of travel and visible need. These projects, however, require large fundraising efforts - which do teach valuable skills - to support travel by a limited subset of the design team. Domestic projects are less expensive, can involve as many or more individuals in the implementation process, and can be repaired much more easily when things break. The argument that domestic projects lack cultural exposure is limited at best - different urban neighborhoods often show large contrasts in values, infrastructure, and needs. The same problems of translating community desires to a functional, acceptable and ethical design exist in domestic settings, but partners and work sites can be reached via local bus. This accessibility means greater and continued engagement and educational impact for a greater number of students.

Shorter projects minimize leadership transition problems. Many projects stall or stutter because passionate student leaders graduate without clearly selecting successors or not leaving documentation. In contrast the ESW-Smith Cargo Cycle was spearheaded by a passionate leader who had a project scope that was achievable within her tenure at the College. Her presence allowed other students to move in and out and gain project experience without a loss of progress. Shorter projects are more feasible in local settings, and can allow students to make real progress in smaller pieces, avoiding the need to transfer complex projects between leaders that may not be as familiar with all pieces.

Partners help ensure project impact through long-term sustainability. Turnover resulting from graduation and changing extracurricular involvement across academic years can lead to inadequate monitoring of projects over the long term. While students learning may occur, project impact is variable - true sustainability requires monitoring of project results and maintenance beyond initial implementation. All three case studies partnered with organizations that had resources to continue the project beyond the initial phase of ESW involvement, although ESWPitt's partner lacked funding for construction. In the case of the Haiti project, the long-term connection was especially important given the geographic distance between the chapter and the final project location. To the extent possible, chapters and future members should be involved in the long-term sustainability of a project since this provides a valuable learning experience and can inform future designs.

\section{Chapters}

Diversity breeds strength. Sustainability is a highly multidisciplinary area that encompasses many different complex and wicked problems. Having students of all disciplines working simultaneously creates a multi-disciplinary space for unique learning opportunities. Shorter projects initiated by student chapters reinforce the idea of collaboration across diverse stakeholders in a way not provided in the classroom. On the network scale, this approach 
provides entry points for students of all majors to participate. On the network scale, this diversity provides a wider potential set of partners and sponsors and encourages learning and sharing across a broader set of backgrounds than traditional engineering coursework.

There is value in associating with a network. Many ESW projects could be done independently, and many ESW chapters originate as independent groups. Associating with the ESW network provides a shared name and new project ideas, as well as best-practice sharing for similar projects, both digitally and through conferences. Organizations that connect to networks also benefit from active support and leadership training, which helps to ensure a more consistent strength, rather than chapters booming and crashing with the arrival or departure of a priori strong leaders.

Stronger chapters are a result of event participation. The primary factors in whether a chapter is active and engaged are attendance at conferences and contact with ESW-National's Chapter Relations volunteers. Events are often expensive, costing hundreds of dollars per student, but the benefits to both individual learning and organizational strength from experiencing the larger community and building a shared identity are worthwhile - students return enthusiastic about new ideas and with a new network to work with.

Relationship management training is critical. A key (often missing) piece in leadership support is making sure that students know how to build and maintain relationships with partners over time, through leadership transitions and busy periods or summer breaks. ESW has been including this content in annual trainings for chapter leaders, but uptake is still limited to those that actively engage.

\section{Challenges to Replication}

Myriad problems, limited leaders. The skills taught by community-based service learning are well documented, and the number of potential partners and problems - locally or internationally - is enormous. For many schools, however, there are only a limited number of students who are interested in and willing to lead these efforts. We need to identify ways to maximize the impact of volunteer leaders to allow the maximum number of students to participate in extracurricular activities, benefitting students' education as well as impacting more problems.

Extracurricular service learning isn't enough. ESW and other service learning organizations engage thousands of students each year, and we feel that ESW's model offers many benefits, particularly around building leadership skills. The individuals we engage are only a small fraction of total engineers, even with new course-based programs. We still need to figure out the ideal means of engaging students who do not self-select into extracurricular service learning, whether finding ways to move more projects in and out of courses, providing new support for faculty to integrate service learning and sustainability in their coursework, or something entirely different.

Balancing support with command. Top-down systems can lead to individual units chafing from a lack of flexibility (a micromanagement problem). In contrast, a bottom-up system without central support mechanisms leads to many weak units with minimal impacts. ESW had experience with the latter from 2009-2011. Support and connections need to be available to maintain and strengthen weak chapters, as does oversight for higher-risk situations like international work. However, sustainability issues require localization, and thus require autonomy for individual 
chapters to select what matters most to their communities. Finally, there is a desire to let students learn and lead while providing advice to avoid serious problems.

\section{Conclusions}

Tackling the wicked problems inherent in sustainability requires many types of organizations, as well as new approaches to service learning that equip technical students with the ability to identify and understand complex problems, engage multiple stakeholders, and design solutions that are relevant to the local context in which they are implemented. Our experience has shown that networked organizations such as ESW can provide this education through extracurricular service-learning projects supported by a network of volunteers, students, faculty, and professionals. The high degree of autonomy given to chapters and the broad topical focus with an emphasis on stakeholder engagement allows students to develop leadership and critical thinking skills while making real impact in their communities. Furthermore, the ability to tangibly experience the impact on the surrounding communities, learn to measure it, and accomplish more with less funding is an advantage of working domestically rather than internationally. Though difficulties always exist in undertaking multiple extracurricular projects, our experience has been that students and faculty are eager to engage with ESW because it provides a valuable aspect of learning by doing for all students involved.

Going forward, we hope to see additional collaboration between collegiate institutions, professional societies, international development groups, and topic-focused networks such as ESW. The lessons presented here show that diverse involvement can be an advantage for both educational goals and sustainability impacts, and certainly the only way to address wicked problems is by combining the strengths of different organizational structures. Service learning projects provide a key format for students to expand their education, particularly when supported by extracurricular groups. We hope that ESW's experience can prove useful to the service learning community or sustainability educators as a whole, as these are problems we all face together, with solutions found through collaboration and knowledge sharing. 


\section{REFERENCES}

H. W. Rittel and M. M. Webber, "Dilemmas in a general theory of planning," Policy sciences, vol. 4, pp. 155-169, 1973.

The Climate Change Educational Partnership: Climate Change, Engineered Systems, and Society: A Report of Three Workshops: The National Academies Press, 2014.

T. Seager, E. Selinger, and A. Wiek, "Sustainable Engineering Science for Resolving Wicked Problems," Journal of Agricultural and Environmental Ethics, vol. 25, pp. 467484, 2012.

L. Klotz, G. Potvin, A. Godwin, J. Cribbs, Z. Hazari, and N. Barclay, "Sustainability as a Route to Broadening Participation in Engineering," Journal of Engineering Education, vol. 103, pp. 137-153, 2014.

5 J. L. Hess, S. A. Brownell, and A. T. Dale, "The Wicked Problems in Sustainable Engineering (WPSE) Initiative: Pilot Results of a Cross-Institutional Project-Based Course Offering," in ASEE 2014 Annual Meeting, Indianapolis, IN, 2014.

Grécourt Gate. (2013, September 30). Catering Cuts Carbon Footprint with Cargo Cycle. Available: http://www.smith.edu/news/catering-cuts-carbon-footprint-with-cargo-cycle/

G. Guido, "Pitt students champion Vandergrift sustainable energy projects," in Pittsburgh Tribune-Review, ed, 2011.

K.-H. Robèrt and R. Anderson, The Natural Step story: Seeding a quiet revolution: New Society Publishers Gabriola Island, 2002.

K. Smith. (2012), ESW project relieves Haiti health center. The Rensselaer Polytechnic. Available: http://poly.rpi.edu/2012/09/12/ESW_project_relieves_haiti_health_center/ 